\title{
Testicular infarction in the newborn: ultrasound findings
}

\author{
J.M.Zerin ${ }^{1}$, M. A. DiPietro ${ }^{1}$, A. Grignon ${ }^{3}$ and D.Shea ${ }^{2}$ \\ Departments of Radiology, ${ }^{1}$ C.S. Mott Children's Hospital, University of Michigan Medical Center, Ann Arbor, Michigan, \\ ${ }^{2}$ Mid-Maine Medical Center, Waterville, Maine, USA, and \\ ${ }^{3}$ Hôpital Sainte-Justine, Montreal, Quebec, Canada
}

Received: 1 September 1989; accepted: 25 October 1989

\begin{abstract}
Three patients with neonatal testicular torsion and infarction (two bilateral, one unilateral) are presented with a distinctive sonographic appearance. All five testes appeared inhomogeneously hypoechoic and each was surrounded by a brightly echogenic rim. Whereas surgical exploration was required in the past to establish the diagnosis of testicular infarction in the neonate, sonographic demonstration of the abnormality in the appearance of the testicular parenchyma permits nonoperative diagnosis. Because surgical salvage of the testis in the setting of neonatal extravaginal torsion is thought to be quite rare, the necessity of removing the testis is less clear when the diagnosis is established preoperatively.
\end{abstract}

The sonographic appearance of the infarcted testis in neonatal torsion has been described in several case reports, with the testis being of inhomogeneous echogenicity [1-2]. We report three neonates with testicular infarction (two bilateral, one unilateral). All five infarcted testes were of diffusely inhomogeneous echogenicity. In addition, a brightly echogenic margin was noted surrounding the testis in each case, an appearance which has not been previously described.

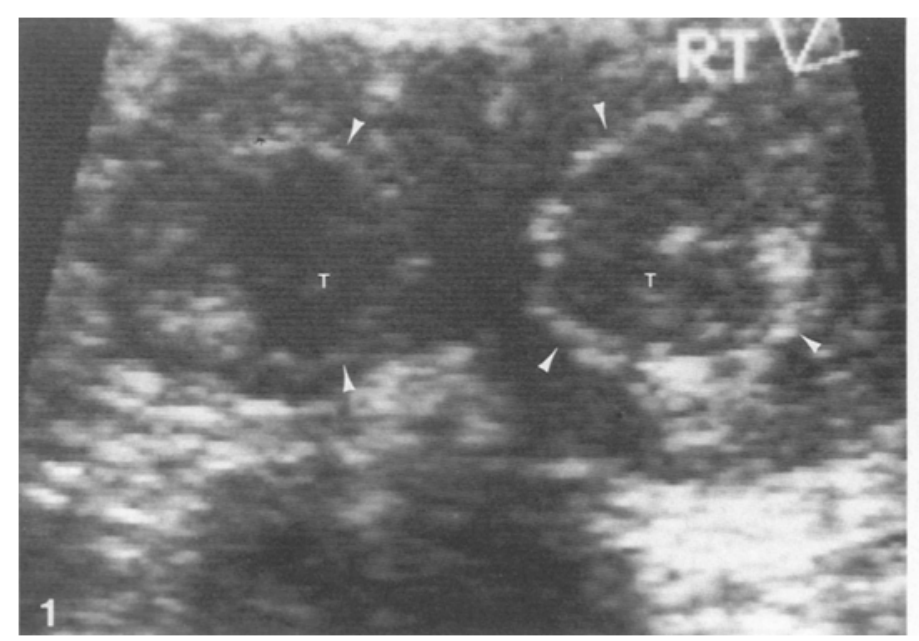

Fig. 1. Case 1. Scrotal ultrasound (transverse view). Both testes (T) are inhomogeneously hypoechoic and surrounded by an echogenic rim (arrowheads)

\section{Case reports}

Case No. 1

This $3200 \mathrm{~g}$ term newborn was noted to have bilateral blue-red scrotal swelling. Pregnancy and delivery were uncomplicated. The baby was otherwise well. The swelling and discoloration subsided over the next few days.

At six weeks of age, both testes were small and hard. Sonographically, the testes were inhomogeneously hypoechoic and each testis was surrounded by a brightly echogenic rim. Small bilateral hydroceles were also present (Fig. 1).

Scrotal exploration at eight weeks of age revealed bilateral torsion of the spermatic cords. Bilateral orchiectomies were done. On microscopic examination there was severe bilateral subacute and chronic hemorrhagic necrosis of the testes and epididymides.

\section{Case No. 2}

This full term newborn boy, product of a normal gestation, had bilateral, firm, symmetrical testicular enlargement. The child was otherwise well. Scrotal scintigraphy was inconclusive. Scrotal sonogxaphy showed large, symmetrical, inhomogeneously hypoechoic testes, each surrounded by a distinct echogenic margin (Fig. 2).

Bilateral scrotal exploration was done. On opening the stretched right tunica albuginea, brownish fluid emerged. Right radical or-

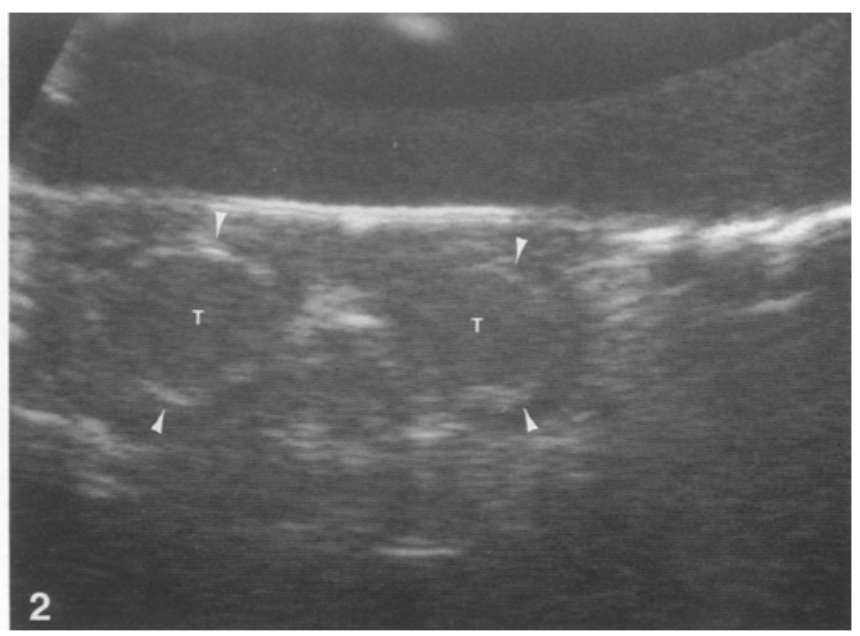

Fig. 2. Case 2. Scrotal ultrasound (transverse view) Both testes (T) are inhomogeneously hypoechoic and surrounded by an echogenic rim (arrowheads) 


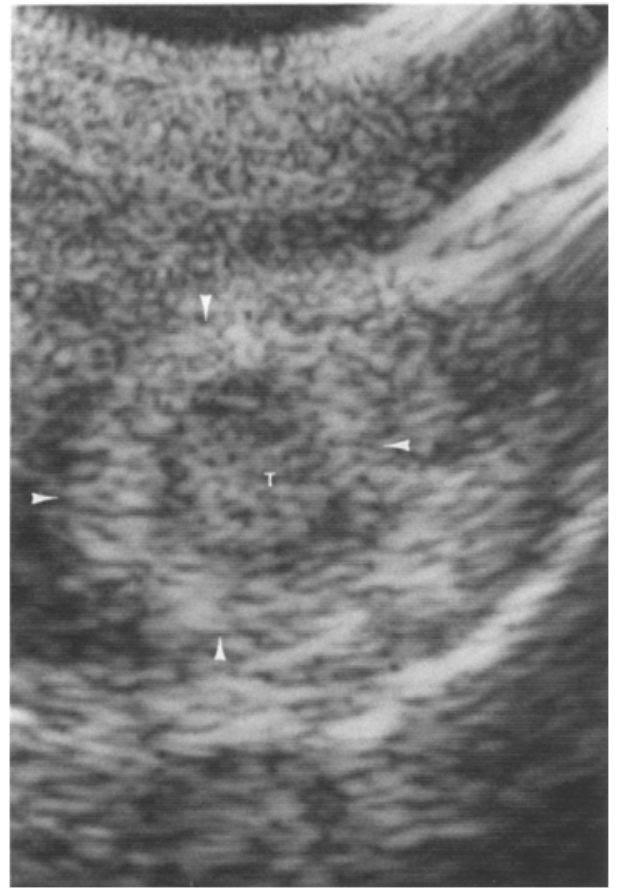

Fig. 3. Case 3. Scrotal ultrasound (coronal view). The left testis (T) has an inhomogeneous echotexture and is surrounded by a thick echogenic rim (arrowheads)

chiectomy and left testicular biopsy were done. Histologically, there was severe hemorrhagic necrosis of the testes, with no visible normal testicular tissue. The boy recovered uneventfully. The left testis has subsequently atrophied.

\section{Case No. 3}

This full term boy was the product of a normal pregnancy and delivery. At two days of age his left scrotum was noted to show a bluered discoloration, and seemed to be tender. The left testis felt firm. At sonography the left test is was inhomogeneously hypoechoic with a thick hyperechoic rim. A small hydrocele was also present (Fig. 3). The right testis appeared normal. Infarction of the left testis was suspected and at follow-up the left testis had atrophied. Orchiectomy was not done.

\section{Discussion}

Extravaginal torsion of the spermatic cord resulting in hemorrhagic infarction of the testis can occur either in utero or during the neonatal period [3-5]. At this age torsion occurs at the level of the spermatic cord (extravaginal) as opposed to the usual intravaginal torsion occurring in the adolescent. The scrotum is enlarged and edematous and the overlying scrotal skin is often discolored. In most cases torsion is unilateral, although bilateral torsion has been reported [6-7]. Frequently the infant is otherwise asymptomatic.

The cause of extravaginal torsion is unknown although it may be related to the stress of labor and delivery [4] or to predisposing developmental abnormality [8]. Torsion results in hemorrhagic infarction with necrosis of the testis, with subsequent fibrosis and occasionally calcification.
Torsion occurring in utero may be the cause of congenital anorchia [9].

In dogs the testis becomes homogeneously hypoechoic acutely following devascularization [10]. The appearance is similar in adolescents and adults with acute torsion [11-12]. However, this appearance is unusual in neonates. Extravaginal torsion usually occurs in utero [1]. As a result, most neonates present with subacute or chronic torsion and hemorrhagic infarction of the testis resulting in a more inhomogeneous parenchymal pattern. The presence of an echogenic rim marginating the testis, as in our cases, suggests the diagnosis of infarction. This appearance may be due to edema or fibrosis of the tunica albuginea. Alternatively, it may be due to a relative increase in echogenicity of the coverings of the testis as the infarcted testis itself undergoes necrosis.

Whereas surgical exploration was required in the past to establish the diagnosis of testicular infarction in the neonate, sonographic demonstration of the abnormality in the appearance of the testicular parenchyma permits non-operative diagnosis. Surgical salvage of the testis in the setting of neonatal extravaginal torsion has been reported [3]; however, it is thought to be quite rare [1]. As a result, removal of the affected testis may not be necessary when the diagnosis is established preoperatively.

Acknowledgement. J. Mandell, M.D. for his advice and encouragement.

\section{References}

1. Hubbard AE, Ayers AB, MacDonald LM, James CE (1984) In utero torsion of the testis: Antenatal and postnatal ultrasonic appearances. Br J Radiol 57: 644

2. Zafaranloo S, Gerard PS, Wise G (1986) Bilateral neonatal testicular torsion: Ultrasonographic evaluation. J Urol 135: 589

3. Auldist AW, Ferguson RS (1975) Torsion of the testes in the newborn. Aust NZ J Surg 45: 14

4. Leach JE, Masih BK (1983) Neonatal torsion of testicle. Urology 16: 604

5. Jerkins GR, Noe HN, Hollabaugh RS, Allen RG (1983) Spermatic cord torsion in the neonate. J Urol 29: 121

6. Atallah MW, Ippolito JJ, Rubin BW (1976) Intrauterine bilateral torsion of the spermatic cord. J Urol 116: 128

7. LaQuaglia MB, Bauer SB, Eraklis A, Feins N, Mandell J (1987) Bilateral neonatal torsion. J Urol 138: 1051

8. James T (1953) Torsion of the spermatic cord in the first year of life. Br J Urol 25: 56

9. Aynsely-Green A, Zachmann M, Illig R, Rampini S, Prader A (1976) Congenital bilateral anorchia in childhood: a clinical, endocrine and therapeutic evaluation of twenty-one cases. Clin Endocrinol 5: 381

10. Hricak H, Lue T, Filly RA, Alpers CE, Zeineh SJ, Tanagho EA (1983) Experimental study of the sonographic diagnosis of testicular torsion. J Ultrasound Med 2: 349

11. Bird K, Rosenfield AT, Taylor KJW (1983) Ultrasonography in testicular torsion. Radiology 147: 527

12. Carroll BA, Gross DM (1983) High-frequency scrotal sonography. AJR 140: 511

J.M.Zerin, M.D.

Section of Pediatric Radiology

C.S. Mott Children's Hospital

University of Michigan Medical Center

1500 E. Medical Center Drive

Ann Arbor, Michigan 48109-0252, USA 